stress that our study was conf ined to ice-shelf responses; discharge from ice streams into the ice shelf was held constant throughout. Currently, we are incorporating this response by including a simple analytic treatment of ice streams that will provide first-order estimate of ice-stream discharge. In brief, we believe the effects of ice-stream feedback are to reduce ice-shelf thinning rates and to increase ice velocities.
REFERENCES

MacAyeal D R 1984 Tides, tidally-driven barotropic circulation and the formation of tidal fronts below the Ross Ice Shelf, Antarctica. Annals of Glaciology 5: 216-217

MacAyeal D R, Thomas R H 1982 Numerical model ing of ice-shelf motion. Annals of Glaciology 3: 189-194

Weertman J 1957 Deformation of floating ice shelves. Joumal of Glaciology 3(21): 38-42

\title{
COMPUTER SIMULATION OF THE ICE SHEET IN THE SHIRASE BASIN, ANTARCTICA
}

\author{
(Abstract) \\ by \\ M. Nagao, M. Nakawo and A. Higashi \\ (Department of Applied Physics, Faculty of Engineering, Hokkaido University, \\ Sapporo 060, Japan)
}

\begin{abstract}
A three-dimensional numerical model is developed to simulate the variation with time of the form of the ice sheet in the Shirase basin, Antarctica (Fig.1). The model is composed of two-dimensional grids on which the mass flux of ice is computed so as to satisfy the equation of continuity. Local conditions of the flow of ice, particularly the effect of the depth profile of temperature, are considered. Adopting a simple method for calculating the mass flux developed by the same authors (Nagao and others 1982) procedures of numerical calculations are simplified. Areal grids of $50 \mathrm{~km}$ distances covering the bas in are used, paying special attention to the boundary conditions at its margin and glacier tongue.

Results of the calculations show that a nearly stable form of the ice sheet could be obtained after approximately $10 \mathrm{ka}$ when started from $1000 \mathrm{~m}$ ice thickness all over the basin. The obtained stable
\end{abstract}

surface topography shows its sensitive dependence on the bedrock topography. There was a tendency for the bottom temperature of the glacier downstream to be higher than the melting point, which may confirm the suggested instability of the ice sheet near the central stream line of Shirase Glacier (Mae 1979).

\section{REFERENCES}

Mae S 1979 The basal sliding of a thinning ice sheet, Mizuko Plateau, East Antarctica. Joumal of Glaciology 24(90): 53-61

Nagao M, Nakawo M, Higashi A 1982 A simple method for calculating mass flux in an ice sheet, with a consideration of its temperature profile. Memoirs of National Institute of Polar Research. Special Issue 24: 192-200 


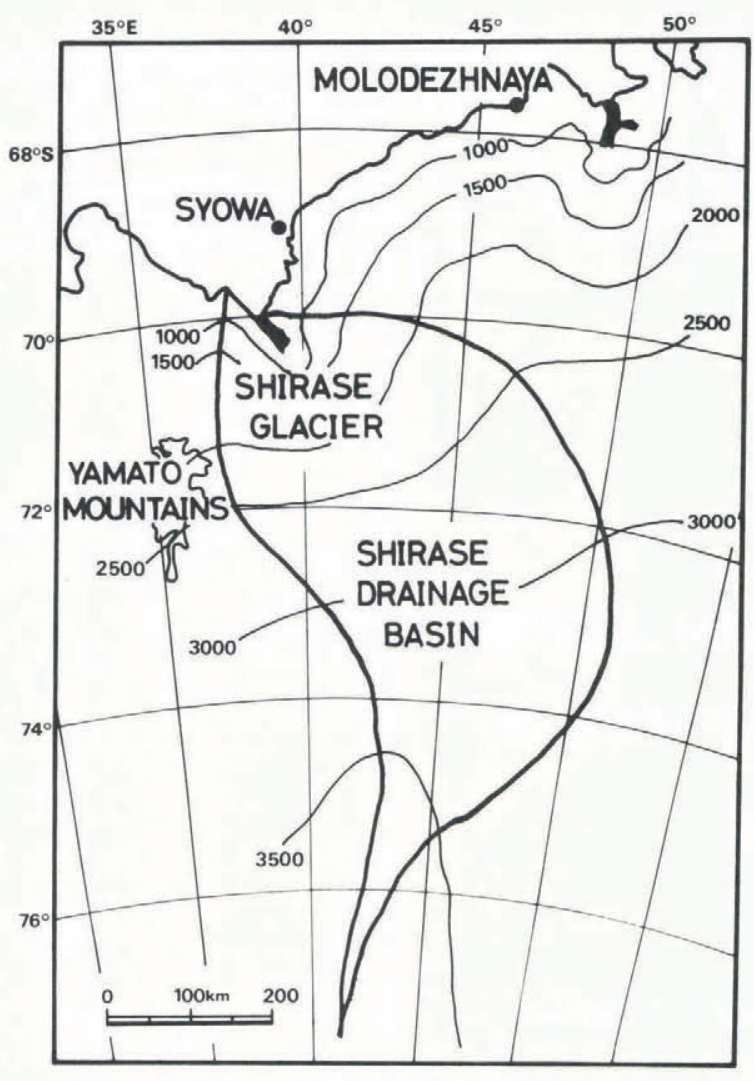

(a) Area map of the drainage basin of Shirase Glacier.

ICE SURFACE HEIGHT(M)

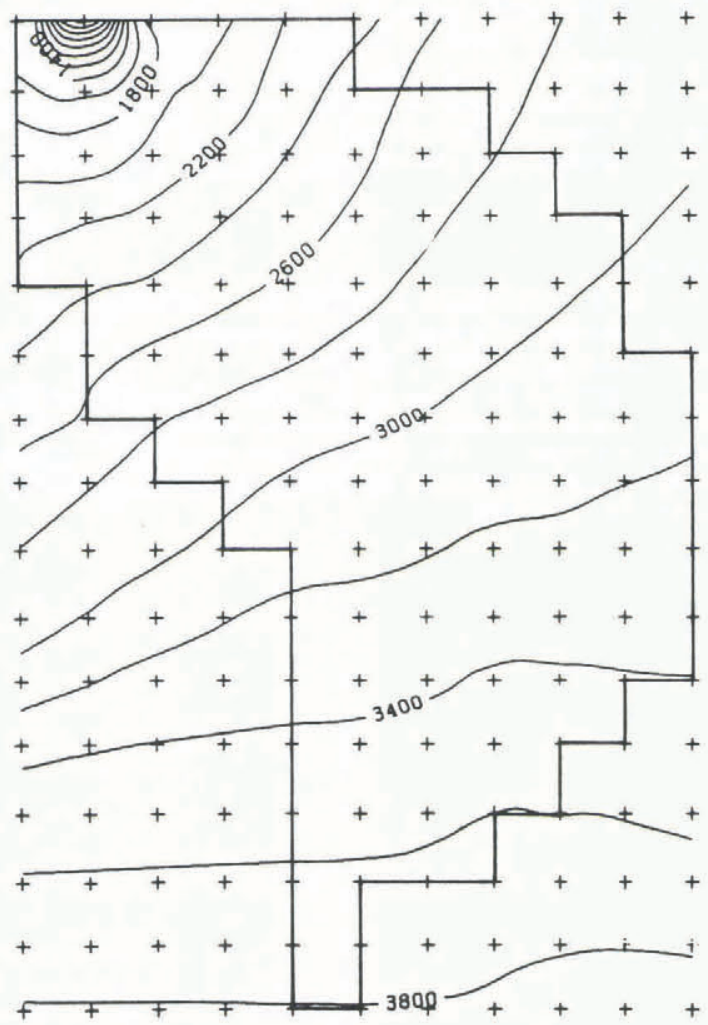

(c) Output results of the height of ice surface.
BED ROCK HEIGHT (M)

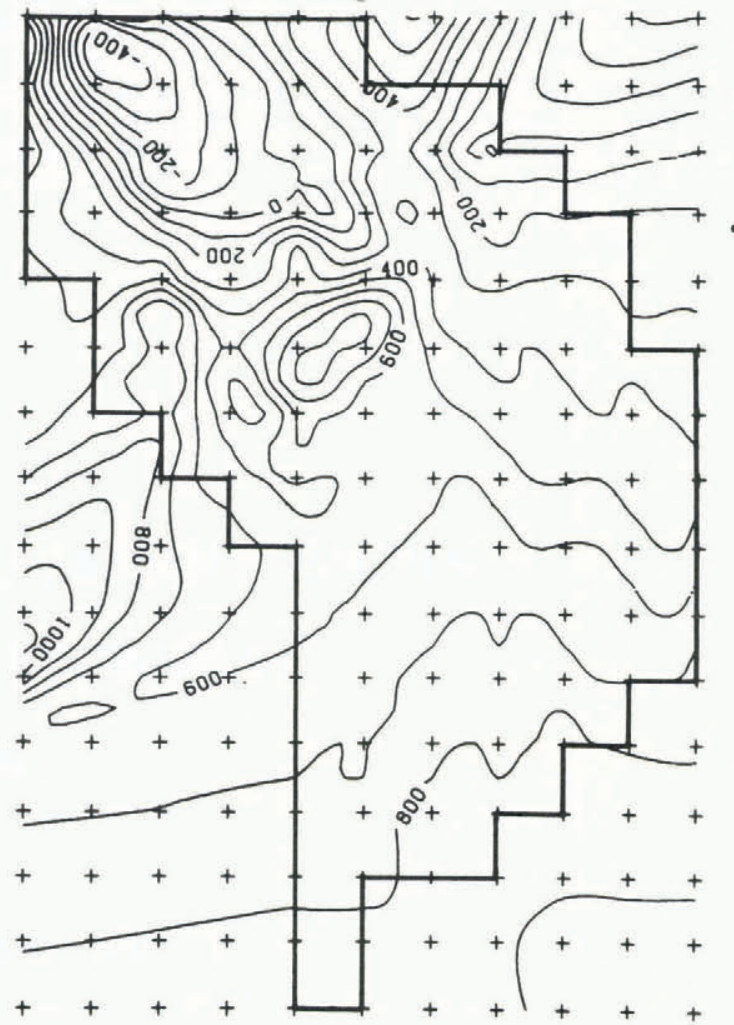

(b) Input data of the bedrock elevation.

SURFACE VELOCITY (DM/A)

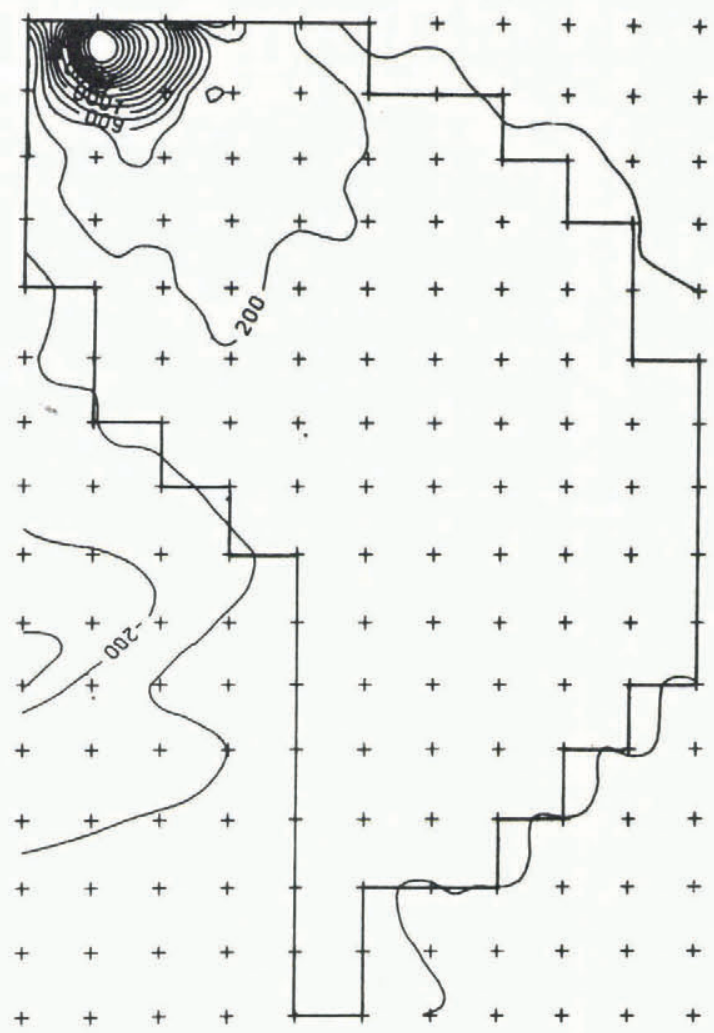

(d) Distribution of the surface velocity of the ice sheet.

Fig.1. (For details, see next page.) 
BED VELOCITY (DM/A)

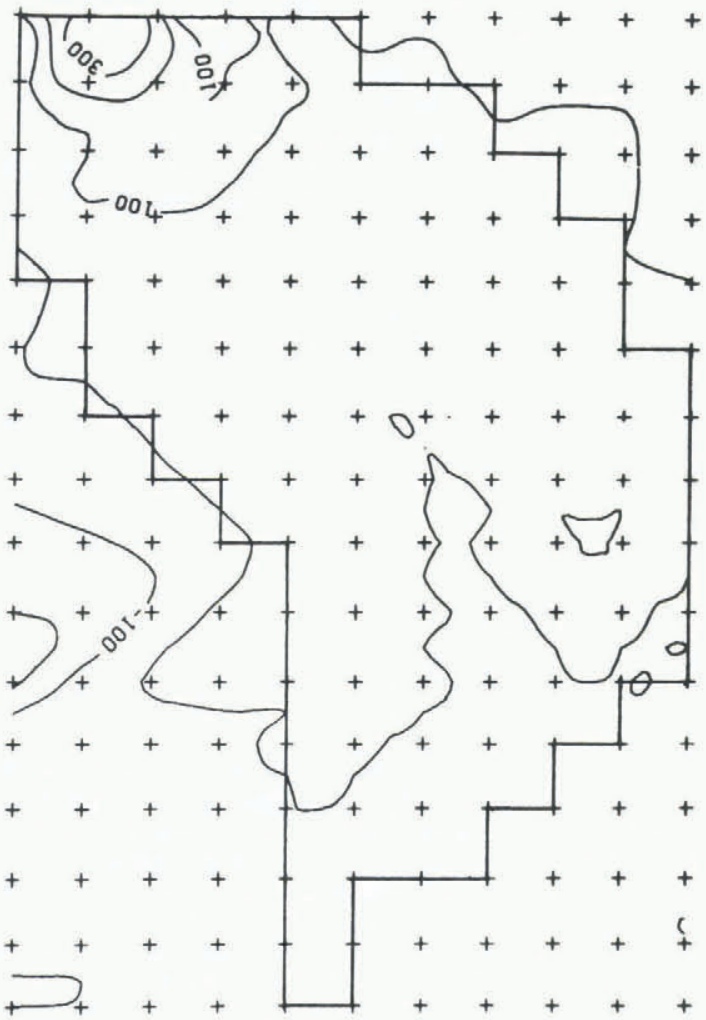

(e) Velocity of ice at the bottom of the ice.
BED TEMPERATURE (C)

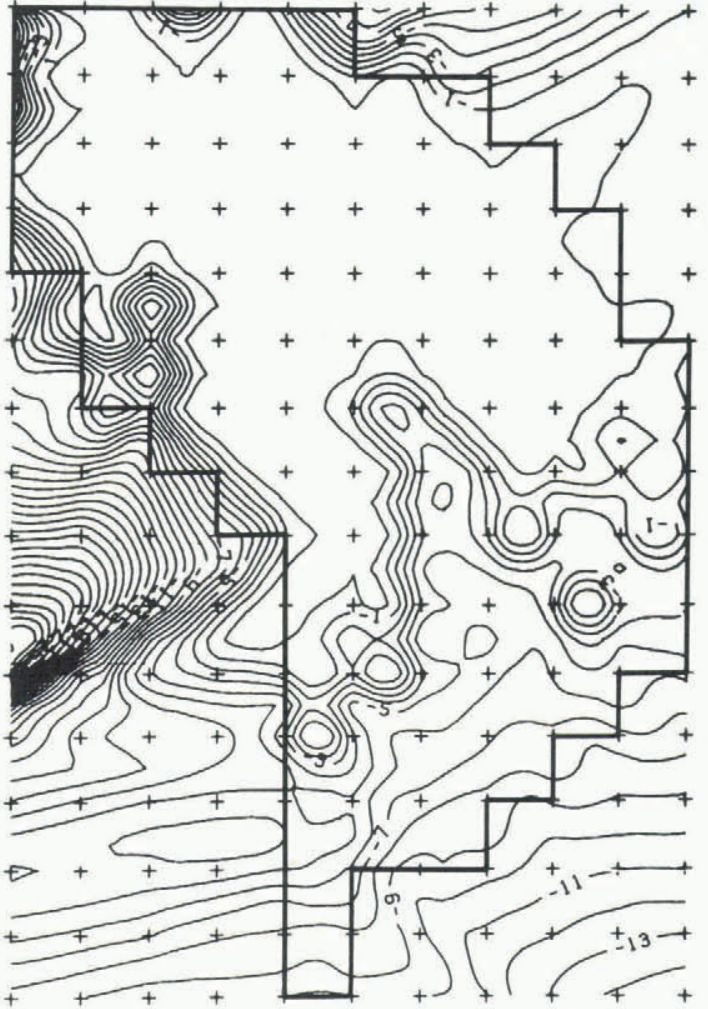

(f) Temperature at the bottom of the ice.

Fig.1. An example of the computer simulation. Details of calculations including initial and boundary conditions (input data) will be given elsewhere. Output results $40 \mathrm{ka}$ after glaciation started from homogeneous 1 000 m ice thickness are shown in $(c),(d),(e)$ and $(f)$.

\title{
A MODEL OF THE ANTARCTIC ICE SHEET INCLUDING
}

\section{THERMODYNAMICS}

\section{(Abstract)}

\author{
by
}

\section{J. Oerlemans}

(Instituut Meteorologie en Oceanografie, Rijksuniversiteit Utrecht, Princetonplein 5, Utrecht 2506, The Netherlands)

Much of the research work on the dynamics of large ice sheets has employed the "flowline approach" (e.g. Young 1981). However, present-day computer facilities now allow the use of two- and three-dimensional models as well. This opens up the possibility of simulating the transient behaviour of large ice sheets, including the effects of irregular bedrock topography, ice shelves, accumulation distribution, etc.

This presentation reports an attempt to construct a time-dependent, two-dimensional (i.e. vertically integrated) model of the entire Antarctic ice sheet. The basic model has been described in 0erlemans (1982). on a grid of $100 \mathrm{~km}$ spacing, it calculates horizontal ice-mass discharge using a constant flow parameter, bedrock adjustment, and the distribution of ice shelves. The evolution of the ice sheet is then obtained from the continuity equation. In this model the ice-accumulation rate depends on temperature, surface slope and distance to open water.
The model has recently been refined by including a calculation of the temperature field in the ice sheet and the associated feedback on the ice-mass discharge. This involves the dependence of internal deformation on ice temperature as well as increased sliding when basal water is present.

Results from this model version indicate that a large part of the West Antarctic ice sheet is always subject to basal melting, even if surface temperature drops by $5 \mathrm{~K}$. The East Antarctic ice sheet, on the other hand, shows a tendency to behave periodically, much in the same way as described in 0erlemans (1983). The period of oscillation is typically $10 \mathrm{ka}$ but depends strongly on such factors as iceaccumulation rate, sea-level temperature, and particularly on how the effect of basal water production on ice-mass discharge is parameterized.

Future work will concentrate on this last point, and also on how reduction of normal pressure by 